\title{
WORK MOTIVATION PROFILES AND WORK PERFORMANCE IN A GROUP OF CORPORATE EMPLOYEES: A TWO-STEP CLUSTER ANALYSIS
}

Few studies have applied a person-centered approach to work motivation using cluster or profile analyses. Thus, little is known about which configurations of work motivations characterize professionals. The aim of this study is to establish the structure of work motivation profiles under the framework of self-determination theory and to examine the relationship between work motivation and subjective work performance. The study involved 147 corporate employees who completed the Multidimensional Work Motivation Scale and self-rated their work performance. The two-step cluster analysis was applied, followed by a one-way ANOVA and a post-hoc Bonferroni test. The findings revealed differences between the five profiles for all forms of motivational regulation on the self-determination continuum (large effect sizes). Further examination revealed that the employees' current work performances differed across motivational profiles (medium effect size). Strongly and poorly motivated as well as autonomously motivated employees reported better subjective work performance compared to unmotivated individuals. In line with self-determination

Correspondence concerning this article can be sent to BEATA A. BASIŃSKA, PhD, Habil., Faculty of Management and Economics, Gdańsk University of Technology, Narutowicza 11/12, 80-233 Gdańsk, Poland; e-mail: beata.basinska@pg.edu.pl; ORCID: https://orcid.org/0000-00026532-7093.

This work was supported by the National Science Centre, Poland [grant no. UMO2017/27/B/HS4/01033]. All the procedures performed in the studies involving human participants were in accordance with the 1964 Helsinki declaration and its later amendments or comparable ethical standards. Informed consent was obtained from all the individual participants included in the study.

I would like to thank Beata Gumienna and Olga Szwichtenberg for their involvement in the recruitment process and for helping me with data collection. I am particularly grateful to prof. Anna Maria Dåderman for her assistance in accessing EBSCOhost database during my study visit at University West, Trollhättan, Sweden. 
theory, the quantity and shape of motivation can be simultaneously considered in terms of both theoretical and practical implementation.

Keywords: work motivation profiles; self-determination theory; two-step cluster analysis; corporate employees; subjective work performance; transnational organizations.

In self-determination theory (SDT), motivation is defined as multiple facets which represent different forms of behavioral regulation stretched along a self-determination continuum (Gagné \& Deci, 2005; Ryan \& Deci, 2000, 2017). These forms of motivation vary in the perceived locus of causality from external to internal, and they can be viewed as having controlling or informational feedback. Motivation can prompt employees to do something, be sustained as they pursue goals and facilitate their drive in a particular trajectory to achieve a specific outcome. Motivation contributes to the development of optimal functioning by employees, and it ensures that organizations perform efficiently (Ryan \& Deci, 2000). Some employees are highly motivated while others are less motivated to put effort into their work. Every year, more transnational organizations are becoming employers as they hire new workers. These organizations expect highly motivated employees to achieve goals and increase organizational profits. Transnational organizations need employees who want to share their skills, knowledge, and achievements, as this constitutes a form of capital with which organizations can build a competitive advantage in the labor market. Working conditions in these organizations are characterized by high requirements for performance in exchange for a variety of organizational resources (e.g., non-wage benefits and opportunities for learning and development) (Delmestri \& Brumana, 2017; Rozkwitalska, 2019). These practices can stimulate extrinsic work motivation, which may come from external pressures, such as remuneration, benefits and recognition, or from internal incentives such as hedonic pleasure or eudaimonic purposefulness (Deci et al., 2017; Gagné et al., 2015). In contrast, intrinsic motivation can be separated from instrumental reasons because those who experience such motivation find work-related activity to be interesting and fun for its own sake (Ryan \& Deci, 2000).

SDT proposes a multidimensional view on motivation that also allows for the assessment of both the level and quality of motivation (Gagné et al., 2015, p. 179). However, little is known about how multiple motivations interact within employees. For example, searches for the terms "motivation" and "latent profile analysis" or "latent class analysis" yielded 103 papers in the EBSCOhost data- 
base (available January 21, 2020). Thirty-nine of these papers referred to the context of work, although not all of them examined motivation profiles.

In response, the current study contributes to both the theoretical and practical understanding of work motivation by including all forms of motivational regulation proposed by SDT, applying two-step cluster analysis to establish work motivation profiles and examining how these profiles relate to subjective work performance in a group of employees working in transnational organizations.

\section{Self-Determination Theory in the Context of Work}

SDT is a theory of human motivation which evolved from a dichotomy of intrinsic and extrinsic motivations to a continuum of self-determination (Deci et al., 2017; Ryan \& Deci, 2017). As a result, it is important to recognize how individuals perceive the locus of causality or their competence (Ryan \& Deci, 2000, 2017). The diversity of forms of motivation is a consequence of differences in individuals' degrees of autonomy, internalization and integration of values, and behavioral regulation (Deci \& Ryan, 2012; Gagné \& Deci, 2005). SDT postulates a distinction between amotivation (an impersonal orientation), forms of controlled motivation (i.e., external regulation — both material and social—and introjected regulation) and autonomous motivation (i.e., identified regulation and intrinsic regulation) which are spread across the self-determination continuum (Gagné et al., 2015; Howard et al., 2016).

Amotivation is defined as a lack of intention to act and an unwillingness to work (Ryan \& Deci, 2000). It characterizes employees who feel incompetent and are unable to complete the tasks expected of them in their work (Gagné et al., 2015). Thus, amotivation is the absence of desire to make any effort and a felt lack of competence to perform (Howard et al., 2016; Ryan \& Deci, 2020).

Controlled forms of motivation are externally or internally regulated (Gagné et al., 2015; Ryan \& Deci, 2020). External regulation refers to becoming involved in an activity for instrumental reasons. Employees who are externally regulated make the effort because they want to receive rewards and avoid punishment. However, rewards can be classified in various ways. For example, some employees desire material rewards such as remuneration, benefits, or job security (material extrinsic regulation), while others seek social approval, recognition and fame (social extrinsic regulation). Controlled motivation, such as introjected regulation, is partially internalized and based on an individual's own internal system of rewards and punishments. It drives employees to act because they are seeking pleasure (e.g., pride in oneself) and avoiding discomfort (e.g., feeling 
shame), with the result that the self-esteem is contingent on outcomes (Ryan \& Deci, 2020).

Autonomous forms of motivation are related to more intrinsically regulated activities which propel employees to achieve a sense of independence, pursue mastery and perceive work as meaningful and purposeful (Gagné et al., 2015; Pink, 2009). The two specific forms of autonomous motivation are identified regulation and intrinsic regulation. Identified regulation is fully internalized extrinsic motivation, which is autonomously regulated due to an internal locus of control. Employees want to act because they identify their work with their personal values or because they find it meaningful; they accept work-related activity as a manifestation of their own will, not the result of external requirements or pressure. Intrinsic regulation involves activities which are interesting, exciting and fun for their own sake. As a consequence, work is a source of satisfaction and happiness. Intrinsic regulation and identified regulation share the quality of being highly volitional, but they differ in that the former is based on fun, while the latter is related to activities perceived as worthwhile, even if they are not enjoyable (Ryan \& Deci, 2020).

Thus, more precise recognition of the degree of motivation (how much motivation is involved in fulfilling one's expected job roles) and the shape of motivation (what composition of motivation forms is desirable) is a promising direction for research (Ryan \& Deci, 2020).

\section{Profiles of Employees' Work Motivation}

Many studies based on a variable-centered approach have examined how each isolated motivation relates to specific outcomes. According to SDT, employees can be motivated in different ways, e.g., by various forms of controlled or autonomous motivation (Gagné \& Deci, 2005; Van den Broeck et al., 2013). Moreover, the forms of motivational regulation are not mutually exclusive (Deci et al., 2017). Employees can be intrinsically motivated, e.g., in relation to clients, but on the same workday they can feel a lack of motivation, e.g., to perform boring tasks. A person-centered approach is thus helpful in understanding how multiple motivations interact within employees and how different combinations of motivational regulation relate to organizational outcomes.

Previous studies usually identified three to six profiles which differed in degree (quantity) and shape (quality) of motivational regulation (e.g., Graves et al., 2015; Walther et al., 2017; Weske \& Schott, 2018). Consistent, low, moderate, and high levels of all forms of regulation were observed (Chen et al., 
2019; Fernet et al., 2020), namely poorly, moderately, and strongly motivated employees. In terms of the shape of work motivation, profiles referred to combinations of controlled and autonomous motivation in opposite quantity (Van den Broeck et al., 2013; Walther et al., 2017; Weske \& Schott, 2018). Here are some examples.

Van den Broeck et al. (2013) identified four profiles of work motivation from combinations of controlled and autonomous regulation in a sample Belgian population, and in samples from different public and private organizations. Some profiles were characterized by high levels of autonomous and controlled motivation, a high level of autonomous and a low level of controlled motivation, a high level of controlled and a low level of autonomous motivation, and finally low levels of autonomous and controlled motivation. The results indicated that over half of the employees presented two motivational profiles. The first was coherent in the quantity of motivation (a high level of autonomous and a high level of controlled motivation), and the second was specific in the shape of motivation (a high level of autonomous and a low level of controlled motivation).

Howard et al. (2016) found four motivation profiles in heterogeneous samples of Canadian and Belgian employees. They represented amotivation, balanced motivation (also namely poorly motivated), moderately autonomous (preferred identified and intrinsic regulation) and highly motivated (high in all forms of regulation). In this study, most employees belonged to a profile characterized by balanced motivation that was low in all forms of regulation.

Gillet et al. (2018) revealed four profiles of motivation in employees from various French companies. Two profiles preferred high levels of autonomous motivation or high levels of autonomous motivation combined with introjected regulation. The next two profiles featured moderate or low levels of all forms of regulation. The profile of the largest group of employees $(60 \%)$ was characterized by high levels of autonomous motivation and low levels of introjected and external regulation. However, this study was based on four forms of regulation (i.e., intrinsic, identified, introjected, and external); it did not include amotivation.

In the context of work, it is difficult to find employees who are driven only by pure intrinsic motivation (Tóth-Király et al., 2020). In contrast, profiles representing unmotivated employees, sometimes called non-self-determined, and poorly motivated, are usually observed (Gillet et al., 2018; Howard et al., 2016).

The multiple facets and complexity of work motivation (involving six specific types of motivation) encourage the application of a person-centered approach. The current study examines a sample of professionals who constitute 
a constantly growing group employed by transnational organizations which are part of the economic globalization trend. To address the issue, two questions were formulated: What structure of motivation profiles can be established in corporate employees? How do these profiles of work motivation differ according to the types of motivation in the framework of SDT?

\section{Organizational Outcomes of Work Motivation}

It is interesting how different profiles of motivation, in contrast to separate motivation, relate to certain organizational outcomes. There is some evidence that more autonomous forms of motivation (i.e., intrinsic and identified regulation) contribute to personal and organizational benefits (Gagné \& Deci, 2005; Gagné, 2014; Howard et al., 2016). Employees characterized by more autonomous motivational profiles experienced higher levels of work engagement, quality of working life and work satisfaction, as well as lower levels of burnout compared to those with moderately autonomous or more controlled motivation (Christensen et al., 2020; Gagné, 2014; Gillet et al., 2018; Manganelli et al., 2018; Moran et al., 2012).

Further analysis revealed that extrinsic motivation was not related or negatively related to work performance, while intrinsic motivation produced more positive outcomes (Kuvaas et al., 2017). In addition, autonomously and highly motivated employees demonstrated better work performance and less personal costs of work compared to their unmotivated co-workers (Howard et al., 2016). Autonomous motivation was more strongly correlated with quality of performance while external regulations were associated with performance quantity (Cerasoli et al., 2014; Kuvaas et al., 2017). External regulation combined with the absence of autonomous regulation was harmful, while the presence of autonomous forms of motivation neutralized adverse outcomes (Moran et al., 2012; Van den Broeck et al., 2013). Hence it raises two presumptions. First, both autonomous and controlled motivation can be considered simultaneously with regard to work performance (Cerasoli et al., 2014). Second, autonomous forms of motivation can be more important for positive outcomes than controlled regulation (Gagné, 2014; Howard et al., 2016).

The relationship between motivational profiles and work performance is important from an institutional perspective. To respond to this issue, the research question of the current study is: How do different profiles of motivation relate to work performance in corporate employees? 


\section{METHOD}

\section{Participants and Procedures}

The sample population comprised 150 professionals aged between 22 and 64 years $(M=31.5, S D=8.32)$ whose work tenure was between 0.5 and 38 years $(M=8.24, S D=4.5)$. Ninety of the participants were women $(60 \%)$. The participants' professions were identified according to the International Standard of Classification of Occupations and fell into the following categories: office workers (e.g., administrative personnel, salespeople, and customer service personnel; $36 \%$ ), specialists (20\%), and technicians and executive staff (13\%). Most participants held subordinate positions $(85 \%)$ which required a higher level of education (bachelor's or master's degree, 89\%). They worked between 40 and 60 hours per week (the official work time is 40 hours). Only 11 participants worked parttime with schedules that ranged from 15 to 32 hours per week.

The convenience sampling method was applied in which the main criterion was working in transnational organizations. These organizations were located in the Pomerania region (northern Poland) and they mainly represented the following economic sectors (defined according to the International Standard Classification of All Economic Activities): wholesale and retail trade (22\%), information and communication (17\%), and transportation and storage (12\%). However, a plurality of respondents indicated that they worked in other service activities (27\%). The organizations ranged in size between 30 and 100,000 employees. However, some of the respondents described the size of the subsidiary they worked for directly instead of the whole organization.

Participation in the study was voluntary and anonymous. According to the ethical principles included in the Declaration of Helsinki, the subjects, having been informed about the aim of the study and the rules for participation, provided written consent to participate in the sample. Missing data did not exceed $2 \%$. Finally, 147 respondents were included in the sample.

\section{Instruments}

Motivational regulation was evaluated by means of the Polish version of the Multidimensional Work Motivation Scale (MWMS, Gagné et al., 2015; Polish version by Chrupała-Pniak et al., 2017). This scale comprises 18 items, and it measures six aspects of motivational regulation derived from the self-determination continuum (amotivation, material extrinsic regulation, social 
extrinsic regulation, introjected, identified, and intrinsic regulation). Each item is preceded by the question "Why do you put effort into your current job?" The possible answers came from a five-point scale ranging from 1 (very little) to 5 (very strongly). Sample items include the following: "I do not because I really feel that I am wasting my time at work" (amotivation; Cronbach's $\alpha=.81$ ); "To get others' approval (e.g., supervisor, colleagues, family, clients...)" (social extrinsic regulation; Cronbach's $\alpha=.78$ ); "Because others will reward me financially only if I put enough effort in my job (e.g. employer, supervisor...)" (material extrinsic regulation; Cronbach's $\alpha=.73$ ); "Because it makes me feel proud of myself" (introjected regulation; Cronbach's $\alpha=.85$ ); "Because putting effort into this job has personal significance for me" (identified regulation; Cronbach's $\alpha=.67$ ); and "Because I have fun doing my job" (intrinsic regulation; Cronbach's $\alpha=.87$ ). Motivational regulation was calculated as the average of the scores. Higher scores indicated a higher level of a type of regulation. The total MWMS score had an internal consistency of .86 .

Current work performance was based on the employee's self-assessment; it did not include objective organizational indicators. It was measured with the single item "How would you rate your current work performance?" derived from Energy Compass (Schaufeli, 2017). The response format was a rating scale that ranged from 0 to 10 , with the higher scores representing better work performance.

\section{Data Analysis}

The descriptive statistics and r-Pearson correlations for the study variables were calculated using SPSS software, version 25 . In the preliminary analysis, the influence of common method variance (CMV) was tested using a Harman's single-factor analysis (Harman, 1976). Results of the Principal Component Analysis for all latent constructs revealed that one factor explained $43.86 \%$ of the variance in the data. This means that a single factor of the merging variables was inappropriate.

The objective of the two-step cluster analysis was to identify work motivation profiles in employees according to their preference for regulation. Cluster analysis is recommended for segmenting populations because it addresses the multidimensional nature of the construct. Thus, this method allows dividing the respondents into groups exhibiting maximum within-group similarity and between-group differences based on the assumed criteria (Everitt et al., 2011). The first step was to identify pre-clusters. The second step was to refine this 
initial estimate by finding the largest increase in distance between the two closest clusters in each hierarchical clustering stage. In this study, log-likelihood distance was used for continuous variables to specify fixed clusters. All criteria variables were transformed into z-scores. To assess the quality of the obtained solution, an average Silhouette measure of cohesion and separation was applied. This measure reflects the efficacy of a cluster solution in maximizing withincluster homogeneity and between-cluster heterogeneity. An average silhouette coefficient of 0.5 indicated a reasonable solution; less than 0.2 indicated a problematic solution (Tsiptis \& Chorianopoulos, 2009). Further, the ratio of the sizes between the largest cluster and the smallest cluster were calculated. The expected value of the ratio of sizes was below 2, but it should not exceed 3 (Everitt et al., 2011).

To examine the differences between clusters in terms of motivational regulation, a one-way ANOVA with a post-hoc Bonferroni test was used. The effect size was calculated as a partial eta squared. Cohen (1988) provided reference points to define small $\left(\eta^{2}=0.01\right)$, medium $\left(\eta^{2}=0.06\right)$, and large $\left(\eta^{2}=0.14\right)$ effects.

\section{RESULTS}

\section{Descriptive Statistics}

Descriptive statistics and r-Pearson correlations among the study variables are presented in Table 1.

Table 1. Descriptive Statistics and r-Pearson Correlations Among Study Variables $(N=147)$

\begin{tabular}{|c|c|c|c|c|c|c|c|c|}
\hline & $M$ & $S D$ & [1] & [2] & [3] & [4] & {$[5]$} & [6] \\
\hline [1] Amotivation & 1.57 & 0.77 & 0.82 & & & & & \\
\hline [2] Extrinsic regulation-material & 2.91 & 0.98 & 0.01 & 0.73 & & & & \\
\hline [3] Extrinsic regulation-social & 2.27 & 0.93 & -0.03 & $0.63^{*}$ & 0.78 & & & \\
\hline [4] Introjected regulation & 3.27 & 0.95 & $-0.27 *$ & $0.60^{*}$ & $0.44 *$ & 0.85 & & \\
\hline [5] Identified regulation & 2.84 & 1.08 & $-0.27 *$ & $0.38^{*}$ & $0.23 *$ & $0.75^{*}$ & 0.67 & \\
\hline [6] Intrinsic regulation & 3.14 & 1.02 & $-0.31 *$ & $0.30^{*}$ & 0.12 & $0.58^{*}$ & $0.64 *$ & 0.87 \\
\hline [7] Current work performance ${ }^{a}$ & 7.88 & 1.46 & $-0.23 *$ & 0.04 & -0.03 & $0.21^{*}$ & $0.23 *$ & $0.22 *$ \\
\hline
\end{tabular}

Note. ${ }^{\text {a }}$ Range $2-10$. Cronbach's $\alpha$ coefficients are given on the diagonal. $* p<0.01$. 
Among the different forms of motivational regulation, amotivation was weakly and negatively correlated with autonomous and introjected regulation. Extrinsic regulation was associated positively, between weakly and moderately, with autonomous regulation, except for a non-significant correlation between extrinsic social and intrinsic regulation. Introjected regulation, which is a part of controlled regulation, was strongly correlated with autonomous regulation.

Motivational regulation was weakly associated with current work performance. More specifically, current work performance was negatively related to amotivation and positively related to introjected, identified, and intrinsic regulation. Furthermore, current work performance did not correlate significantly with either material extrinsic regulation or social extrinsic regulation.

\section{Work Motivation Profiles}

Next, a two-step cluster analysis was conducted to identify work motivation profiles in employees according to their form of regulation. Fixed clusters between two- and five-cluster solutions based on the sample were determined. The evaluations of the quality of the solutions are presented in Table 2.

Table 2. Fit Statistics of Two-Step Cluster Analysis: Specifying Fixed Clusters

\begin{tabular}{lcccc}
\hline $\begin{array}{c}\text { Number } \\
\text { of clusters }\end{array}$ & $\begin{array}{c}\text { Cluster } \\
\text { quality }^{\mathrm{a}}\end{array}$ & $N$ per cluster & Ratio of sizes $^{\mathrm{b}}$ & $\begin{array}{c}\text { Predictor importance } \\
\text { (above 0.8) }\end{array}$ \\
\hline 2 & 0.4 & 92,55 & 1.67 & $\begin{array}{c}\text { Introjected regulation } \\
\text { Identified regulation }\end{array}$ \\
3 & 0.3 & $47,67,33$ & 2.03 & Introjected regulation \\
5 & 0.3 & $26,27,61,33$ & 2.35 & Amotivation \\
5 & 0.4 & $24,26,41,30,26$ & 1.71 & $\begin{array}{c}\text { Amotivation; } \\
\text { Introjected regulation }\end{array}$ \\
\hline
\end{tabular}

Note. ${ }^{\mathrm{a}}$ Average silhouette measure of cohesion and separation. ${ }^{\mathrm{b}}$ Largest-to-smallest cluster.

The findings indicated that the average silhouette measure of cohesion and separation indicated that two- and five-cluster solutions were acceptable, and they were better than three- and four-cluster solutions. Moreover, the value of the ratio of sizes between clusters was not greater than 2 for two- and five-cluster solutions. To be specific, the two-cluster solution was based on quantitative differences (strongly vs poorly motivated), whereas the five-cluster solution referred to both quantitative and qualitative differences in work motivation. 
Moreover, the clusters that varied in the shape of motivation were related to the self-determination continuum (amotivation, controlled and autonomous regulation). The five-cluster solution was thus identified to be optimal with regard to statistical adequacy and best suited to the theoretical framework derived from SDT (see Figure 1).

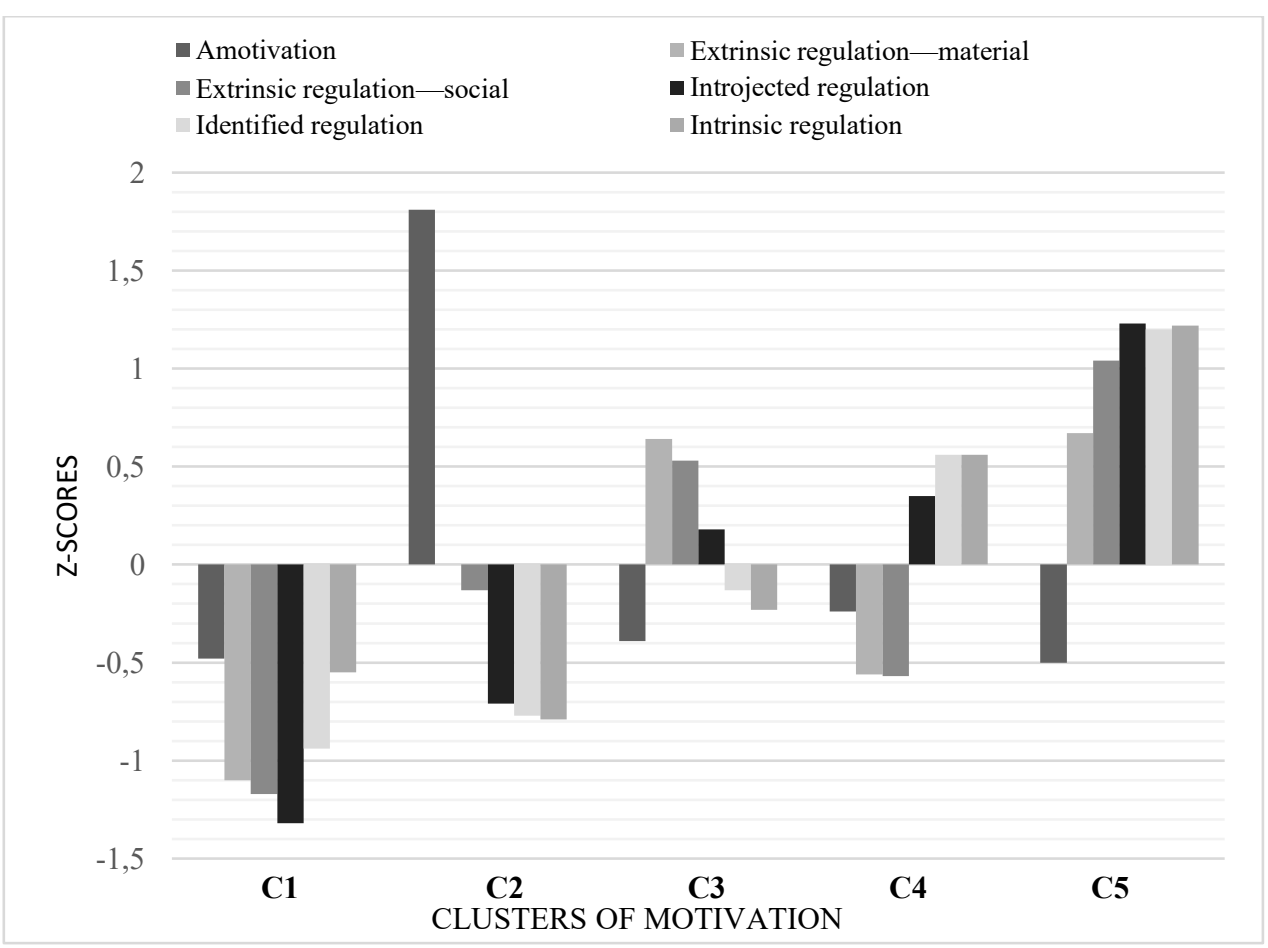

Note. $\mathrm{C} 1=$ poorly motivated, $\mathrm{C} 2=$ unmotivated employees, $\mathrm{C} 3=$ controlled motivation, $\mathrm{C} 4=$ autonomous motivation, $\mathrm{C} 5=$ strongly motivated.

Figure 1. Z scores for Motivational Regulations of Five-Cluster Solution

Figure 1 shows the z-scores for each subscale of motivational regulation in the five different clusters. In the first cluster (16.3\% of the sample), labeled "poorly motivated," employees were characterized by low scores for all forms of motivational regulation. In the second cluster (17.7\% of the respondents), "unmotivated employees" presented the highest level of amotivation, low levels of introjected and autonomous regulation, and average levels of extrinsic regulation, both social and material. The third cluster ( $27.9 \%$ of the respondents) was 
labeled "controlled motivation." It reflected high levels of extrinsic and average levels of introjected, identified, and intrinsic regulation. The fourth cluster (20.4\% of the sample) was named "autonomous motivation." Employees in that cluster were characterized by high levels of identified and intrinsic regulation, a moderate level of introjected regulation and low levels of extrinsic regulation, both material and social. The fifth cluster (17.7\% of the respondents) was called "strongly motivated." Those employees had the highest scores for all forms of regulation except amotivation, for which they had the lowest scores.

\section{Differences Between Profiles in Terms of Motivational Regulation and Work Performance}

A one-way ANOVA was conducted to examine in detail the differences within groups in terms of motivational regulation (see Table 3 ). The findings indicated significant differences across the groups for all forms of motivational regulation on the self-determination continuum. The scores obtained were as follows: amotivation $\left(\eta^{2}=0.723\right)$, material $\left(\eta^{2}=0.457\right)$ and social extrinsic regulation $\left(\eta^{2}=0.562\right)$, introjected regulation $\left(\eta^{2}=0.679\right)$, identified regulation $\left(\eta^{2}=\right.$ $=0.576$ ), and intrinsic regulation $\left(\eta^{2}=0.469\right)$. All effect sizes were large (see Table 3).

Results of a post-hoc Bonferroni test revealed that unmotivated employees demonstrated a lack of work motivation. Material and social extrinsic regulation scores were the highest in employees who experienced controlled motivation and those with strong motivation. Introjected regulation and identified regulation were preferred by employees who reported autonomous motivation, but they were avoided by those who were unmotivated or poorly motivated. Intrinsic regulation was preferred by employees who experienced autonomous motivation and in those who were strongly motivated.

Corporate employees rated their current work performance at a fairly high level $(M=7.88, S D=1.46$, range $2-10)$. Moreover, an examination of current work performance indicated that it differed according to motivational profiles $\left(\eta^{2}=0.098\right.$; medium effect size $)$. Results of the post-hoc Bonferroni test showed that subjective ratings of current work performance were the highest in the strongly motivated as well as the poorly motivated employees, followed by autonomously motivated employees, whereas the lowest score were obtained in the unmotivated individuals. 
Table 3. Mean Scores for Motivational Clusters and ANOVA of Study Variables for Motivational Clusters

\begin{tabular}{|c|c|c|c|c|c|c|c|}
\hline & $\begin{array}{c}\mathrm{C} 1 \\
n=24 \\
16.3 \%\end{array}$ & $\begin{array}{c}\mathrm{C} 2 \\
n=26 \\
17.7 \%\end{array}$ & $\begin{array}{c}\text { C3 } \\
n=41 \\
27.9 \%\end{array}$ & $\begin{array}{c}\mathrm{C} 4 \\
n=30 \\
20.4 \%\end{array}$ & $\begin{array}{c}C 5 \\
n=26 \\
17.7 \%\end{array}$ & $F$ & $\begin{array}{c}\text { Post-hoc } \\
\text { Bonferroni } \\
\text { test }\end{array}$ \\
\hline \multicolumn{8}{|c|}{ Cluster dimension (z-scores) } \\
\hline Amotivation & -0.48 & 1.81 & -0.39 & -0.24 & -0.50 & & \\
\hline $\begin{array}{l}\text { Extrinsic } \\
\text { regulation } \\
\text { - material }\end{array}$ & -1.10 & 0.00 & 0.64 & -0.56 & 0.67 & & \\
\hline $\begin{array}{l}\text { Extrinsic } \\
\text { regulation } \\
\text { - social }\end{array}$ & -1.17 & -0.13 & 0.53 & -0.57 & 1.04 & & \\
\hline $\begin{array}{l}\text { Introjected } \\
\text { regulation }\end{array}$ & -1.32 & -0.71 & 0.18 & 0.35 & 1.23 & & \\
\hline $\begin{array}{l}\text { Identified } \\
\text { regulation }\end{array}$ & -0.94 & -0.77 & -0.13 & 0.56 & 1.20 & & \\
\hline $\begin{array}{l}\text { Intrinsic } \\
\text { regulation }\end{array}$ & -0.55 & -0.79 & -0.23 & 0.56 & 1.22 & & \\
\hline \multicolumn{8}{|c|}{ Cluster dimension (raw scores) } \\
\hline Amotivation & 1.21 & 2.96 & 1.28 & 1.39 & 1.19 & $92.74 *$ & $2>1,3,4,5$ \\
\hline $\begin{array}{l}\text { Extrinsic } \\
\text { regulation } \\
\text { - material }\end{array}$ & 1.83 & 2.91 & 3.54 & 2.37 & 3.56 & $29.89^{*}$ & $\begin{array}{c}5=3>1,2,4 \\
2>1\end{array}$ \\
\hline $\begin{array}{l}\text { Extrinsic } \\
\text { regulation } \\
\text { - social }\end{array}$ & 1.64 & 2.60 & 3.21 & 2.20 & 3.68 & $17.55^{*}$ & $\begin{array}{c}1<2,3,4,5 \\
5>4,3,2 \\
3>4,2\end{array}$ \\
\hline $\begin{array}{l}\text { Introjected } \\
\text { regulation }\end{array}$ & 2.02 & 2.60 & 3.45 & 3.60 & 4.44 & $75.12 *$ & $\begin{array}{c}1<2,3,4,5 \\
5>4,3,2 \\
4,3>2\end{array}$ \\
\hline $\begin{array}{l}\text { Identified } \\
\text { regulation }\end{array}$ & 2.12 & 2.31 & 3.00 & 3.75 & 4.44 & $48.24 *$ & $\begin{array}{c}5>4,3,2,1 \\
4>3 \\
4,3>1=2\end{array}$ \\
\hline $\begin{array}{l}\text { Intrinsic } \\
\text { regulation }\end{array}$ & 2.28 & 2.04 & 2.60 & 3.23 & 4.08 & $31.38 *$ & $\begin{array}{c}5>4,3,2,1 \\
4>3,2,1 \\
3>2,1\end{array}$ \\
\hline $\begin{array}{l}\text { Current } \\
\text { work per- } \\
\text { formance }\end{array}$ & 8.25 & 7.00 & 7.76 & 8.13 & 8.31 & 3.85 & $2<1,4,5$ \\
\hline
\end{tabular}




\section{DISCUSSION}

The aim of this study was to establish the structure of work motivation profiles under the framework of SDT by using a two-step cluster analysis and to examine the relationship between work motivation profiles and subjective work performance. Five motivational clusters were identified which differed with respect to the level of motivation (quantity differences) and their shape (qualitative differences). There were poorly or strongly motivated employees as well as unmotivated employees, and employees preferred controlled or autonomous motivation. The findings also indicated differences between profiles for all forms of motivational regulation on the self-determination continuum. Moreover, strongly and poorly motivated as well as autonomously motivated employees reported better subjective work performance compared to unmotivated individuals.

These findings are consistent with previous studies which demonstrated that identified work motivation profiles varied in the quantity of motivation and shape of motivation (Gillet et al., 2018; Howard et al., 2016; Van den Broeck et al., 2013). The shapes of the profiles were usually built as a combination of opposing levels of controlled and autonomous motivations, whereas quantitative profiles reflected a balance and partnership between different forms of motivational regulation. Simultaneous consideration of the quantity of motivation together with the shape of motivation along the self-determination continuum is meaningful in theoretical and practical reasons (Howard et al., 2018).

Poorly motivated corporate employees presented various forms of motivation in lesser but equal degrees. This combination has been called balanced motivation (Howard et al., 2016). In the current study, poorly motivated employees reported average self-ratings of their work performance, which suggests that, despite their low motivation to work, these employees fulfilled their professional roles and achieved their goals in line with the expectations of the organization. Salanova et al. (2014) identified a similar profile of well-being, which they called the "9 to 5" or relaxed employee. These individuals were competent and efficacious at work, but they complained of a lack of enthusiasm, and they reported low identification and strong intentions to leave the organization.

Two groups of corporate employees, the unmotivated and those who preferred controlled motivation, accounted for nearly half of the respondents. These groups shared an interest in extrinsic regulation that can be detrimental to work performance (Kuvaas et al., 2017). Previous studies also have identified unmotivated employees, constituting 11-28 per cent of the sample populations (Howard et al., 2016). The current results indicated that unmotivated employees reported 
relatively high levels of external regulation. This suggests that they expect contingent rewards such as remuneration, benefits, and recognition despite their reluctance to work. They also reported the lowest level of subjective work performance among the participants. Therefore, it is possible that due to their great sense of incompetence, employees with an impersonal orientation cannot understand the reasons for their behavior and unwillingness to accomplish goals (Malinowska \& Tokarz, 2020).

The results demonstrated that around 40 per cent of respondents presented two motivational profiles: coherent in the quantity of motivation (strongly motivated), and specific in the shape of motivation (autonomously motivated). Strongly motivated employees reported somewhat higher subjective work performance than the autonomously motivated. In like manner, Fernet et al. (2020) found that strongly and moderately motivated employees were associated with higher in-role performance compared to self-determined employees (i.e., high in autonomous motivation). Prior findings also showed that there were no differences between these two profiles in terms of well-being (Christensen et al., 2020; Gagné, 2014; Tóth-Király et al., 2020). These employees were satisfied with work and engaged in it, and they did not feel symptoms of burnout. Both groups experienced a high level of autonomous motivation that could be a protective function (Moran et al., 2012; Van den Broeck et al., 2013). Taken together, these findings appear to support the idea that the degree of work motivation and its shape are simultaneously significant.

This study has some shortcomings. First, the two-step cluster analysis was applied. In future studies, latent profile analysis is recommended because it provides more advanced indicators of a solution's goodness of fit. Second, the convenience sampling method was used. This method limits the ability to generalize from the findings to the population of corporate employees. Third, current work performance was measured solely by self-evaluation. In further research, it would be better to use ratings based on supervisors' assessments or objective indicators of productivity. Fourth, this study is a part of a larger project focused on the motivational regulation of employees and their productivity. The answer format of the MWMS was therefore modified to a five-point scale because it had to be adjusted so it could be used with other instruments (the original answer format was based on a seven-point scale). Despite these limitations, the current findings are consistent with self-determination theory and they complement the results from prior studies. 


\section{THEORETICAL AND PRACTICAL IMPLICATIONS}

Research in work organizations considers the perspectives of employees and management. This means that work-related well-being is just as important as work performance and productivity. In fact, some companies (and specific managers within companies) are known to disregard their employees' well-being in an effort to increase profits. Despite that, identifying work motivation profiles and implementing effective management is beneficial for both employees and employers, as it enables the creation of work policies and good practices, as well workplace designs which promote both well-being and high-quality work performance (Deci et al., 2017).

Managers and human resources personnel can be encouraged to promote autonomous regulation to enhance the functioning of their subordinates. First of all, they can assess employees' motivation to achieve particular organizational outcomes and the specific gratifications they want. They can also restructure job designs, support interpersonal relationships between co-workers and leaders and offer fair remuneration in such a way as to meet basic psychological needs (Manganelli et al., 2018). Promoting an organizational culture which respects employee autonomy can reduce organizational costs.

The essential theoretical contribution of this study is that two-step cluster analysis can be used to exhibit five different profiles regarding the degree and shape of work motivation. Two profiles in particular revealed that different forms of motivation can coexist within individuals at a similar level (poorly or strongly motivated), and three profiles (unmotivated, controlled and autonomous profile) provide evidence that the shape of motivation can be qualitatively diversified. The further contribution of the study is that it can shed new light on the relationship between work motivation and subjective work performance. Strongly and poorly motivated employees, as well as autonomously motivated employees, reported better work performance compared to unmotivated individuals. This clearly shows that employees' impersonal orientation is the most deleterious for work performance. Extrinsic motivation, however, should be balanced by a more autonomous regulation. It means that the quantity and shape of motivation matter in terms of work performance. Accounting for the quantity of motivation together with the qualitative variations along the self-determination continuum illustrates their complementary functions (Howard et al., 2018). This means that employees can expect remuneration, recognition, and even fame for positive organizational results. However, at the same time, they want autonomous, meaningful, and passionate work that promotes personal growth. 


\section{REFERENCES}

Cerasoli, C. P., Nicklin, J. M., \& Ford, M. T. (2014). Intrinsic motivation and extrinsic incentives jointly predict performance: A 40-year meta-analysis. Psychological Bulletin, 140(4), 980 1009. https://doi.org/10.1037/a003566

Chen, C. X., Zhang, J., \& Gilal, F. G. (2019). Composition of motivation profiles at work using latent analysis: theory and evidence. Psychology Research and Behavior Management, 12, 811-824. https://doi.org/10.2147/PRBM.S210830

Christensen, M., Dyrstad, J. M., \& Innstrand, S. T. (2020). Academic work engagement, resources and productivity: empirical evidence with policy implications. Studies in Higher Education, 45(1), 86-99. https://doi.org/10.1080/03075079.2018.1517304

Chrupała-Pniak, M., Chudzicka-Czupała, A., Grabowski, D., \& Paliga, M. (2017). Multidimensional Work Motivation Scale (Gagne et al., 2015) - Wielowymiarowa Skala Motywacji w Pracy - wersja eksperymentalna (Unpublished manuscript). Uniwersytet Śląski, Katowice, Poland.

Cohen, J. (1988). Statistical power analysis for the behavioral sciences. Lawrence Erlbaum Associates.

Deci, E. L., Olafsen, A. H., \& Ryan, R. M. (2017). Self-determination theory in work organizations: The state of a science. Annual Review of Organizational Psychology and Organizational Behavior, 4(1), 19-43. https://doi.org/10.1146/annurev-orgpsych-032516-11 3108

Deci, E. L., \& Ryan, R. M. (2012). Self-determination theory. In P. A. M. van Lange, A. W. Kruglanski, \& E. T. Higgins (Eds.), Handbook of theories of social psychology (pp. 416-436). Sage Publications. https://doi.org/10.4135/9781446249215.n21

Delmestri, G., \& Brumana, M. (2017). The multinational corporation as a playing field of power: A Bourdieusian approach. Multinational Corporations and Organization Theory: Post Millennium Perspectives (Research in the Sociology of Organizations), 49, 325-353. https://doi.org/10.1108/S0733-558X20160000049011

Everitt, B. S., Landau, S., Leese, M., \& Stahl, D. (2011). Cluster Analysis (5th ed.). John Wiley \& Sons.

Fernet, C., Litalien, D., Morin, A. J., Austin, S., Gagné, M., Lavoie-Tremblay, M., \& Forest, J. (2020). On the temporal stability of self-determined work motivation profiles: A latent transition analysis. European Journal of Work and Organizational Psychology, 29(1), 49-63.

Gagné, M. (2014). The Oxford handbook of work engagement, motivation, and self-determination theory. Oxford University Press.

Gagné, M., \& Deci, E. L. (2005). Self-determination theory and work motivation. Journal of Organizational Behavior, 26(4), 331-362. https://doi.org/10.1002/job.322

Gagné, M., Forest, J., Vansteenkiste, M., Crevier-Braud, L., Van den Broeck, A., Aspeli, A. K., ... Halvari, H. (2015). The Multidimensional Work Motivation Scale: Validation evidence in seven languages and nine countries. European Journal of Work and Organizational Psychology, 24(2), 178-196. https://doi.org/10.1080/1359432X.2013.877892

Gillet, N., Fouquereau, E., Vallerand, R. J., Abraham, J., \& Colombat, P. (2018). The role of workers' motivational profiles in affective and organizational factors. Journal of Happiness Studies, 19(4), 1151-1174. https://doi.org/10.1007/s10902-017-9867-9 
Graves, L. M., Cullen, K. L., Lester, H. F., Ruderman, M. N., \& Gentry, W. A. (2015). Managerial motivational profiles: Composition, antecedents, and consequences. Journal of Vocational Behavior, 87, 32-42. https://doi.org/10.1016/j.jvb.2014.12.002

Harman, H. H. (1976). Modern factor analysis (3rd ed.). University of Chicago Press.

Howard, J. L., Gagné, M., Morin, A. J., \& Forest, J. (2018). Using bifactor exploratory structural equation modeling to test for a continuum structure of motivation. Journal of Management, 44(7), 2638-2664. https://doi.org/10.1177/0149206316645653

Howard, J., Gagné, M., Morin, A. J., \& Van den Broeck, A. (2016). Motivation profiles at work: A self-determination theory approach. Journal of Vocational Behavior, 95, 74-89. https://doi.org/10.1016/j.jvb.2016.07.004

Kuvaas, B., Buch, R., Weibel, A., Dysvik, A., \& Nerstad, C. G. (2017). Do intrinsic and extrinsic motivation relate differently to employee outcomes? Journal of Economic Psychology, 61, 244-258. https://doi.org/10.1016/j.joep.2017.05.004

Malinowska, D., \& Tokarz, A. (2020). The moderating role of Self Determination Theory's general causality orientations in the relationship between the job resources and work engagement of outsourcing sector employees. Personality and Individual Differences, 153, 109638. https://doi.org/10.1016/j.paid.2019.109638

Manganelli, L., Thibault-Landry, A., Forest, J., \& Carpentier, J. (2018). Self-determination theory can help you generate performance and well-being in the workplace: A review of the literature. Advances in Developing Human Resources, 20(2), 227-240. https://doi.org/ $10.1177 / 1523422318757210$

Moran, C. M., Diefendorff, J. M., Kim, T. Y., \& Liu, Z. Q. (2012). A profile approach to self-determination theory motivations at work. Journal of Vocational Behavior, 81(3), 354-363. https://doi.org/10.1016/j.jvb.2012.09.002

Pink, D. H. (2009). Drive: The surprising truth about what motivates us. Penguin.

Rozkwitalska, M. (2019). Learning experiences in mono-and intercultural workplace interactions the job-demands-resources approach. Journal of Workplace Learning, 31(5), 305-323. https://doi.org/10.1108/JWL-11-2018-0140

Ryan, R. M., \& Deci, E. L. (2020). Intrinsic and extrinsic motivation from a self-determination theory perspective: Definitions, theory, practices, and future directions. Contemporary Educational Psychology, 61, 101860. https://doi.org/10.1016/j.cedpsych.2020.101860

Ryan, R. M., \& Deci, E. L. (2017). Self-determination theory: Basic psychological needs in motivation, development, and wellness. Guilford Publications.

Ryan, R. M., \& Deci, E. L. (2000). Self-determination theory and the facilitation of intrinsic motivation, social development, and well-being. American Psychologist, 55(1), 68-78. https://doi.org/10.1037110003-066X.55.1.68

Salanova, M., Del Líbano, M., Llorens, S., \& Schaufeli, W. B. (2014). Engaged, workaholic, burned-out or just 9-to-5? Toward a typology of employee well-being. Stress and Health, 30(1), 71-81. https://doi.org/10.1002/smi.2499

Schaufeli, W. B. (2017). Applying the job demands-resources model. Organizational Dynamics, 2(46), 120-132. https://doi.org/10.1016/j.orgdyn.2017.04.008

Tóth-Király, I., Morin, A. J., Bőthe, B., Rigó, A., \& Orosz, G. (2020). Toward an improved understanding of work motivation profiles. Applied Psychology. https://doi.org/10.1111/ apps. 12256

Tsiptis, K., \& Chorianopoulos, A. (2009). Data mining techniques in CRM: Inside customer segmentation. John Wiley \& Sons. 
Van den Broeck, A., Lens, W., De Witte, H., \& Van Coillie, H. (2013). Unraveling the importance of the quantity and the quality of workers' motivation for wellbeing: A person-centered perspective. Journal of Vocational Behavior, 82(1), 69-78. https://doi.org/10.1016/j.jvb. 2012.11.005

Walther, A., Möltner, H., \& Morner, M. (2017). Non-executive director's motivation to continue serving on boards: A self-determination theory perspective. Corporate Governance: The International Journal of Business in Society, 17(1), 64-76. https://doi.org/10.1108/CG-052016-0120

Weske, U., \& Schott, C. (2018). What motivates different groups of public employees working for Dutch municipalities? Combining autonomous and controlled types of motivation. Review of Public Personnel Administration, 38(4), 415-430. 